\title{
Investigation into the environmental fate of the combined Insensitive High Explosive constituents 2,4-dinitroanisole (DNAN), 1-nitroguanidine (NQ) and nitrotriazolone (NTO) in soil
}

Temple, T. ${ }^{1}$, Ladyman, M. ${ }^{1}$, Mai, N. ${ }^{1}$, Galante, E. ${ }^{1}$, Ricamora, M. ${ }^{1}$, Shirazi, R. ${ }^{1}$, Coulon, F. ${ }^{2}$

${ }^{1}$ Cranfield University, Centre for Defence Chemistry, Defence Academy of the United Kingdom, Shrivenham, SN6 7LA, UK

${ }^{2}$ Cranfield University, School of Water, Energy and Environment, Cranfield, MK43 0AL, UK

\begin{abstract}
Contamination of military ranges by the use of explosives can lead to irreversible environmental damage, specifically to soil and groundwater. The fate and effects of traditional explosive residues are well understood, while less is known about the impact of Insensitive High Explosives (IHEs) that are currently being brought into military service. Current research has focussed on the investigation of individual constituents of IHE formulations, which may not be representative of real-world scenarios when explosive residues will be deposited together. Therefore, this study investigated the fate and transport of the combined IHE constituents 2,4-dinitroanisole (DNAN), 1-nitroguanidine (NQ) and 3nitro-1,2,4-triazol-5-one (NTO) in two UK soil types.
\end{abstract}

Static experiments ran for 9 weeks to determine the fate of the combined explosive constituents in soil by monitoring the rate of degradation. Transport was examined by running soil column experiments for 5 weeks, with a watering regime equivalent to the average yearly UK rainfall. Both static and soil column experiments confirmed that DNAN and NTO started to degrade within twenty-four hours in soil with high organic content, and were both completely degraded within sixty days. NQ was more stable, with $80 \%$ of the original material recovered after sixty days. The major degradation product of DNAN in the test soils was 2-amino-4-nitroanisole (2-ANAN), with trace amounts of 4-amino-2- 
nitroanisole. NTO was rapidly degraded in soil with high organic content, although no degradation products were identified. Results supported work from literature on the individual constituents DNAN, NQ and NTO suggesting that the three explosives in combination did not interact with each other when in soil. This study should provide a useful insight into the behaviour of three combined insensitive high explosive constituents for the predication of soil and water contamination during military training.

Keywords: Fate and transport, explosive degradation, 2-ANAN, 4-ANAN, DAAN 


\section{Introduction}

The chemical components of munitions are released into the environment during manufacture and by detonations through military activities, which has led to environmental contamination (Pichtel and Pichtel, 2012). Studies conducted on over 30 United States (US) military training ranges have shown that explosive contamination is common in surface soils, and can cause long-term irreversible environmental degradation (Jenkins et al., 2006; Walsh MR., Walsh ME., Collins CM., Saari S P., Zufelt J E., Gelvin AB., and Hug J W., 2005). In one particular case, high explosives were detected in groundwater at concentrations two orders of magnitude higher than the advisory drinking water limits (Morley et al., 2006). Transport of the explosives through soil to groundwater is dependent on the soil type in these areas e.g. loamy, sand, chalk or clay. In the United Kingdom (UK) for example, two of the main training areas are located on loamy soil and use imported sand for bullet catching and other training activities.

Traditional explosives such as 2,4,6-trinitrotoluene (TNT), and 1,3,5-trinitroperhydro-1,3,5-triazine (RDX) and their known degradation products are toxic and potential human carcinogens (United States Environmental Protection Agency, 2014a, 2014b), which has led to more stringent environmental governance. The fate and effects of traditional explosive residues are well understood, while less is known about the impact of Insensitive High Explosives (IHEs) that are currently being brought into military service. For example, Insensitive Munitions Explosive (IMX) formulations that consist of mixtures of RDX, 2,4-dinitroanisole (DNAN), 3-nitro-1,2,4-triazol-5-one (NTO) and 1nitroguanidine (NQ) (Lee et al., 2010; Singh et al., 2010). Of particular interest for this paper is IMX-101 which consists of 2,4-dinitroanisole (43\%) (DNAN), 1-nitroguanidine (37\%) (NQ) and 3nitro-1,2,4-triazol-5-one (20\%) (NTO) (Lee et al., 2010). The impact of the three IHE constituents on the environment may be significant, as they are known to be toxic. DNAN is the most toxic with an $\mathrm{LD}_{50}$ of $199 \mathrm{mg} \mathrm{kg}^{-1}$ in rats (Dodd and McDougal, 2001; Williams et al., 2014). This is comparable to the toxicity of RDX (100 mg kg${ }^{-1}$ ), which is known to contaminate soil and groundwater on training ranges and manufacturing sites (Bordeleau et al., 2008; Jenkins et al., 2006; Kalderis et al., 2011; Pichtel and Pichtel, 2012). NTO and NQ are less toxic (Crouse et al., 2015; McCain et al., 2013), but 
still may present a pollution issue under environmental legislation (The Environmental Permitting (England and Wales) Regulations 2010. SI 675., 2010). NTO, DNAN and NQ are susceptible to degradation in the environment to potentially more toxic compounds.

Of the three constituents, DNAN is the most likely component to undergo photo-degradation as it has low solubility (276 mg L $\mathrm{m}^{-1}$ ) and may remain on the soil surface for longer periods of time (Taylor et al., 2017). The photo-degradation products include nitrate ions, ammonium ions, formaldehyde and formic acid, the latter via the intermediates hydroxy-nitroanisole (HO-NAN). Another degradation product has been identified as 2,4-dinitrophenol (DNP), although only in solution and therefore may not represent the degradation products from the breakdown of solid DNAN on the soil surface (Hawari et al., 2015; Rao et al., 2013). DNP is of particular concern as it is more toxic than the parent compound with an $\mathrm{LD}_{50}$ of $30 \mu \mathrm{g} \mathrm{L}^{-1}$. DNAN has a greater affinity for soils with a higher organic content (Olivares et al., 2016), and degrades in soil into amino derivatives such as 2 and 4-aminonitroanisole (2/4-ANAN) and diamino-anisole (DAAN) which have a higher attenuation to soil (Arthur et al., 2017; Hawari et al., 2015).

NTO is the most soluble of the three constituents $\left(16,642 \mathrm{mg} \mathrm{L}^{-1}\right)$ and therefore has the potential to enter the soil at a rate dependent on rainfall (Braida et al., 2012). NTO is not likely to sorb significantly to soils as it is negatively charged at environmentally relevant pH (Mark et al., 2016; Smith and Cliff, 1999). However, NTO is susceptible to degradation in soils with high organic content which may be attributed to bio-degradation as NTO mass loss has been shown to be significantly lower in sterilized soils (Mark et al., 2017a). Microcosm studies have shown that NTO is readily biodegraded to give 3- amino-1,2,4-triazol-5-one (ATO) (Krzmarzick et al., 2015; Le Campion et al., 1999; Richard and Weidhaas, 2014a). Although mass loss of NTO has been readily observed in soil column and batch experiments, ATO has not yet been detected (Mark et al., 2017a).

NQ is more soluble than DNAN (3800 $\mathrm{mg} \mathrm{L}^{-1}$ ) and does not sorb significantly to soil, so it is expected to be transported quickly to groundwater (Mirecki et al., 2006). However, NQ is susceptible to photodegradation and biodegradation in certain organic soils, forming mineralised products such as nitrourea and ammonia (Kaplan and Kaplan, 1985; Richard and Weidhaas, 2014b). 
Table 1 summarises the properties of the three IHE, and their degradation products.

Table 1: Toxicity, solubility and major degradation products of DNAN, NQand NTO

\begin{tabular}{|lccc|}
\hline Explosive & $\begin{array}{c}\text { Solubility } \\
\left(\mathbf{m g ~ L}^{\mathbf{- 1}}\right)^{\mathbf{1}}\end{array}$ & $\begin{array}{c}\text { Oral toxicity } \\
\left(\mathbf{m g ~ k g}^{-\mathbf{1}}\right)\end{array}$ & $\begin{array}{c}\text { Major degradation } \\
\text { products }\end{array}$ \\
\hline DNAN & 276 & $199^{2}$ & $\begin{array}{c}\text { 2-ANAN, 4-ANAN, } \\
\text { DAAN, DNP, 4-HONAN }\end{array}$ \\
\hline NTO & 16,642 & $>5000^{3}$ & ATO \\
\hline NQ & 3800 & $>1000^{4}$ & Nitro-urea, ammonia \\
\hline
\end{tabular}

1. (Taylor et al., 2015); 2. (Dodd and McDougal, 2001); 3. (Williams et al., 2014); 4. (Crouse et al., 2015)

Therefore, the aim of this work was to investigate fate and transport of IHE constituents mixture consisting of DNAN, NQ and NTO in static soil experiments and vertical soil columns under controlled laboratory conditions. The static experiments were set-up to determine the degradation products of the IHE and the soil columns to determine the transport mechanisms and flow properties. Soil types with different percentages of organic content were chosen for these experiments so that the relationship between the soil characteristics and fate and transport of the IHE can be further understood from an environmental impact perspective. The highlight of this research was the investigation of the fate of DNAN, NQ and NTO as a mixture in soil. These compounds are used in combination in explosive formulations and are likely to be deposited in the environment as mixtures, and not as pure compounds.

\section{Materials and Methods}

Samples of NTO and NQ were synthesised in-house at Cranfield University (Lee and Coburn, 1988). DNAN was purchased from Fischer Scientific UK. Analytical samples of ATO and 4-ANAN were purchased from Fluorochem, DAAN was purchased from Sigma Aldrich, 2-ANAN was purchased from Alfa Aesar (Massachusetts, United States) and 2-HONAN and DNP (70\% in water) were purchased from Thermofischer Scientific UK. All analytical samples were $98 \%$ or higher purity and were used without further purification. Methanol (MeOH) and Acetonitrile (ACN) High Performance Liquid Chromatography (HPLC) grade were purchased from Thermofischer Scientific UK. Deionised 
water (DI), $18.2 \mathrm{M} \Omega . \mathrm{cm}$ at $25^{\circ} \mathrm{C}$, from Millipore Synergy) was used for all experiments. Ottawa sand was also purchased from Thermofischer Scientific UK.

\subsection{Soil}

Two soils were purchased from a building merchant in Oxfordshire (UK). The soils were air-dried for 2 weeks and passed through a 2-mm sieve. The soils were characterised by testing for humidity (BS 13772:1990), $\mathrm{pH}$ and total organic content (BS 13039:2001). Total carbon nitrogen hydrogen (TCNH) content and total organic carbon (TOC) were determined using Elementar Vario ELIII. The particle size distribution was determined according to ASTM D 2487-11, which classified the two soils as loamy and sandy. Two control soils were prepared by incinerating samples of the loamy and sandy soil at $400^{\circ} \mathrm{C}$ for 3 days to vaporise all organic material. Ottawa sand was used as a blank. Soil characterisation is summarised in Table 2 .

Table 2: Characterisation of loamy and sandy soil, incinerated soil and Ottawa sand.

\begin{tabular}{|c|c|c|c|c|c|c|c|c|}
\hline \multirow[t]{2}{*}{ Soil } & \multirow[t]{2}{*}{ Description } & \multirow[t]{2}{*}{$\begin{array}{c}\text { Organic } \\
\text { Content }^{1} \\
(\%)\end{array}$} & \multirow[t]{2}{*}{$\begin{array}{c}\text { TOC }^{2} \\
(\%)\end{array}$} & \multicolumn{4}{|c|}{$\begin{array}{c}\mathrm{TCNH}^{3} \\
(\%)\end{array}$} & \multirow[t]{2}{*}{$\mathbf{p H}^{4}$} \\
\hline & & & & $\mathbf{N}$ & $\mathbf{C}$ & $\mathbf{H}$ & $\mathrm{C} / \mathrm{N}$ & \\
\hline Loamy & UK top soil & 8.0 & 4.1 & 0.30 & 5.11 & 0.74 & 17 & 8.0 \\
\hline Sandy & UK sand & 4.9 & 0.43 & 0.012 & 7.22 & 0.30 & 600 & 7.9 \\
\hline Loamy Control & Incinerated loamy soil & 0 & 1.32 & LOD & 1.14 & 0.14 & N/A & 8.1 \\
\hline Sandy Control & Incinerated sandy soil & 0 & 0.06 & LOD & 6.73 & 0.14 & N/A & 7.9 \\
\hline Ottawa Sand & $100 \%$ quartz & - & - & - & - & - & - & 7.1 \\
\hline
\end{tabular}

1. Determined by incineration at $400^{\circ} \mathrm{C}$ for three days; 2. Determined by Elementar Vario ELIII according to British Standard BS 7755 Section 3.8:1995; 3. Determined by Elementar Vario ELIII; 4. Determined by Griffin pH meter model 80; LOD: Limit of Detection.

\subsection{Stock Solutions}

Stock solutions for static experiments were prepared by stirring DNAN (0.423 g), NQ (0.367 g) and NTO $(0.215 \mathrm{~g})$ in DI water $(1,500 \mathrm{~mL})$ at ambient temperature for 72 hours (Stock Solution 1$)$. The solution was filtered prior to use to remove any suspended particulate. The final concentration was 171 ppm DNAN, 97 ppm NTO and 233 ppm NQ as determined by HPLC. Six dispersions were 
prepared for the vertical soil column experiments containing DNAN $(0.9 \mathrm{~g}, 42 \%)$, NQ $(0.8 \mathrm{~g}, 37 \%)$ and NTO $(0.45 \mathrm{~g}, 21 \%)$ in DI $(100 \mathrm{~mL})$. The solutions were sonicated for 2 hours, and left overnight to ensure minimum particle size and maximum dispersion. A third stock solution (DNAN, NTO, NQ $500 \mathrm{ppm}$ ) in ACN/water (1:1) was prepared for HPLC calibration (Stock Solution 2).

\subsection{Static Experiments}

Soil $(10 \mathrm{~g})$ was placed in amber vials $(60 \mathrm{~mL})$ with Stock Solution $1(15 \mathrm{~mL})$. Twelve vials were prepared for each soil type: loamy, sandy, loamy control, sandy control and Ottawa blank and were placed in a sand bath to ensure constant temperature $\left(19.5^{\circ} \mathrm{C}\right)$. One sample of each soil type was sacrificed after ten minutes (T0), further samples were sacrificed at hour 1, 3, 6, 24 and on day 7, 14, 20,38 , on day 62 samples were taken in triplicate. The IHE solution from the sacrificed samples was decanted, filtered and diluted by a factor of eight in a mixture of ACN/water for analysis by HPLC for the parent compounds, and expected degradation products. The remaining soil was extracted with ACN/water (1:1) by shaking for 18 hours at room temperature (Walsh, 2016). The solid phase extract was filtered, diluted by a factor of eight in a mixture of ACN/water (1:1) and analysed by HPLC. Blank samples of the stock solution 1, kept under the same conditions as the samples, were tested periodically to ensure that the experimental conditions were not contributing to breakdown over time. Stock Solution 1 , stored at $5^{\circ} \mathrm{C}$ throughout the experiment, was also evaluated for degradation at every time point.

\subsection{Soil Column Experiments}

Clear Perspex® columns $(10 \mathrm{~cm}$ x $40 \mathrm{~cm})$ with polyvinyl chloride $(\mathrm{PVC})$ collection funnels fitted with stainless steel wire meshes were placed into collection containers (Figure 1). Increments soil (100 g) were added to the column and compacted using a tamping rod $(1.2 \mathrm{~kg})$ until a height of $20 \mathrm{~cm}$ was achieved.(Oliviera et al., 1996) Columns of loamy soil and sandy soil were prepared in triplicate and capped with a wire mesh and an $800 \mathrm{~g}$ weight with a hole through the top for access. The average 
packing density for the loamy soil was $1.27 \pm 0.03 \mathrm{~kg} \mathrm{~L}^{-1}$ and $1.81 \pm 0.02 \mathrm{~kg} \mathrm{~L}^{-1}$ for sandy soil. The columns were saturated with DI water and left to settle for 5 days without eluting water (Figure 1).

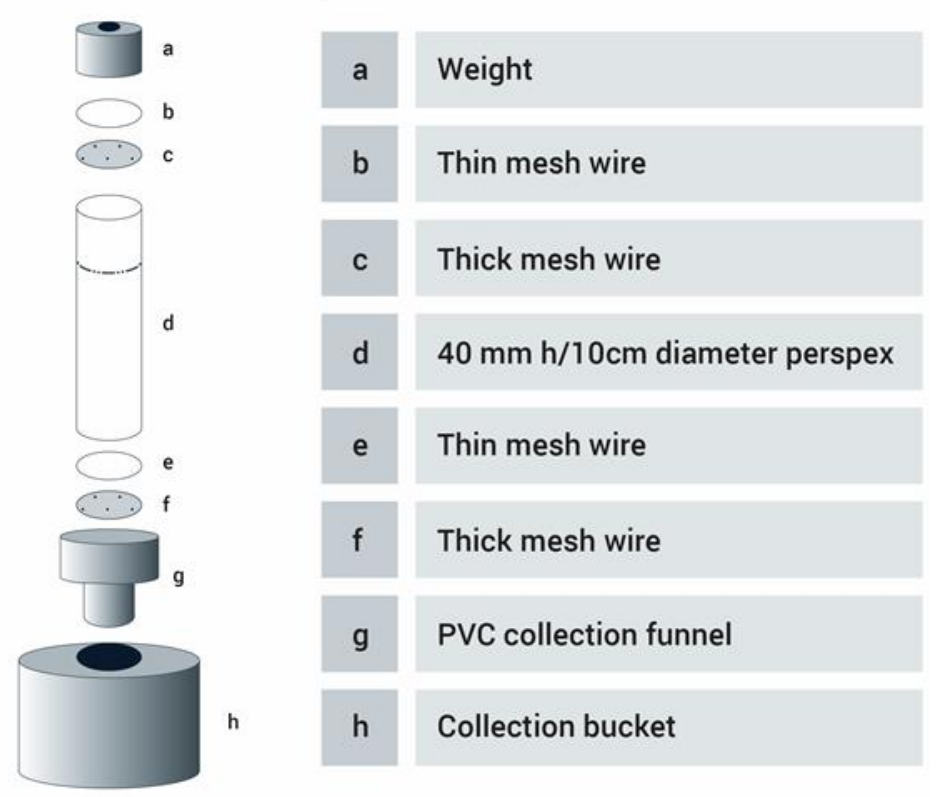

\begin{tabular}{|ll|}
\hline \multicolumn{2}{|l|}{ Loamy Soil Column } \\
\hline Mass & $1270 \pm 30 \mathrm{~g}$ \\
Volume & $1571 \mathrm{~cm}^{3}$ \\
Packing density & $1.27 \pm 0.03 \mathrm{~kg} \mathrm{~L}^{-1}$ \\
Pore volume & $315 \mathrm{~cm}^{3}$ \\
\hline
\end{tabular}

\section{Sandy Soil Column}

Mass $\quad 1810 \pm 20 \mathrm{~g}$

Volume $\quad 1571 \mathrm{~cm}^{3}$

Packing density $\quad 1.81 \pm 0.02 \mathrm{~kg} \mathrm{~L}^{-1}$

Pore Volume $\quad 690 \mathrm{~cm}^{3}$

Figure 1: Schematic showing the construction of the soil columns.

\subsection{Vertical saturated soil columns}

The soil columns were exposed to a volume of water equivalent to the average yearly rainfall in the UK (South West England and Wales) from 1995 to 2015 data calculated to be $1160 \mathrm{~mm}$.(Met Office, n.d.) This is equivalent to the delivery of $9.11 \mathrm{~L}$ of water per column over the 5-week experiment, resulting in an artificial watering scheme representative of a full year's rainfall. The columns were treated with $260 \mathrm{~mL}$ water per day delivered in five increments $(4 \times 60 \mathrm{~mL}$ and $1 \times 50 \mathrm{~mL}) 1$ hour apart at a rate of $40 \mathrm{~mL} \mathrm{m^{-1 }}$ (Kramoer Dosing Pump, China). The leachate was collected weekly and analysed by HPLC within 5 days of collection. Sub-samples were stored at $4^{\circ} \mathrm{C}$, pending analysis. 


\subsection{Accelerated Solvent Extraction}

At the end of the 5 week experiment, the soil columns were disassembled and the loamy soil and sandy soil samples were divided into 4 sections $(5 \mathrm{~cm}$ each). After air-drying for 1 week, the soil was ground (Essa, LM2-P Pneumatic 380V, $50 \mathrm{~Hz}$ ) and the explosives were extracted by Accelerated Solvent Extraction (ASE) (Dionex ASE 350, Thermo Fisher Scientific, UK), using an adapted ASE explosive method to extract the highly water soluble NTO (Dionex, 2011). Samples were extracted using $\mathrm{ACN} /$ water $(3: 2)$ at $100^{\circ} \mathrm{C}$, with a heating time of 5 minutes, a static time of 10 min and a 100 second purge. Using this method, DNAN and NQ were extracted with $100 \%$ efficiency and NTO with $60 \%$ efficiency. The results were corrected accordingly. The resultant extracts were analysed by HPLC.

\subsection{HPLC Analysis}

Collected leachates were analysed by HPLC (Waters-Alliance 2696, USA) using a photodiode array detector (Waters, 996, USA). DNAN, NTO, NQ and degradation products 2-ANAN and 4-ANAN were separated on a ZORBAX Eclipse Plus C18 column $(100 \mathrm{~mm} \times 4.6 \mathrm{~mm}, 3.5 \mu \mathrm{m}$ particle size $)$ from Agilent (Wilmington, DE, USA) maintained at $35^{\circ} \mathrm{C}$. The mobile phase was methanol (solvent A), ACN (solvent B) and water/0.1\% formic acid (solvent C) with a flow rate of $0.75 \mathrm{~mL} \mathrm{~min}{ }^{-1}$. Optimised separation conditions were achieved with a gradient program (Table 2). The injection volume was $10 \mu \mathrm{L}$. Peak identification was performed by comparing the retention time and UV profile of the compounds to standard compounds. The output signals were monitored at a selective reference wavelength as displayed in Table 3. The HPLC method was validated by examining: (i) Specificity (analysis of aqueous solution of wetted soils); (ii) Linearity (measure of the correlation coefficient for each standard from the linear regression analysis in the concentration range of 0.6 to 20 $\mu \mathrm{l} / \mathrm{ml}$ ); (iii) Limit of Detection (LOD), Limit of Quality (LOQ) (measure of the residual standard deviation of the responses and slopes of the regression equation of the calibration curve (root mean 
square error approach)) and (iv) Precision (measure of the relative standard deviation of six injections of each compounds at a concentration of $14 \mu \mathrm{l} / \mathrm{ml}$ ). The results are displayed in Table 3 .

Table 2: Mobile phase gradient program

\begin{tabular}{|cccc|}
\hline $\begin{array}{c}\text { Time } \\
(\text { Min })\end{array}$ & $\begin{array}{c}\text { Solvent A } \\
(\boldsymbol{\%})\end{array}$ & $\begin{array}{c}\text { Solvent B } \\
(\boldsymbol{\%})\end{array}$ & $\begin{array}{c}\text { Solvent C } \\
(\boldsymbol{\%})\end{array}$ \\
\hline $\mathbf{0}$ & 10 & 0 & 90 \\
$\mathbf{2 . 5}$ & 10 & 0 & 90 \\
$\mathbf{3}$ & 5 & 5 & 90 \\
$\mathbf{1 1}$ & 0 & 100 & 0 \\
$\mathbf{1 2}$ & 0 & 100 & 0 \\
$\mathbf{1 6}$ & 10 & 0 & 90 \\
\hline
\end{tabular}

Table 3: Method validation parameters

\begin{tabular}{|lcccc|}
\hline Chemical & $\begin{array}{c}\text { Wavelength } \\
(\mathbf{n m})\end{array}$ & $\begin{array}{c}\text { Linearity } \\
\left(\mathbf{R}^{\mathbf{2}}\right)\end{array}$ & $\begin{array}{c}\text { LOD/LOQ } \\
(\boldsymbol{\mu l} \mathbf{l} \mathbf{m l})\end{array}$ & $\begin{array}{c}\text { Precision } \\
(\boldsymbol{\%})\end{array}$ \\
\hline NQ & 264 & 0.9996 & $0.5 / 1.6$ & 0.8 \\
DNAN & 296 & 0.9999 & $0.5 / 1.4$ & 0.6 \\
NTO & 315 & 0.9995 & $0.5 / 1.4$ & 0.8 \\
2-ANAN & 308 & 0.9999 & $0.2 / 0.7$ & 0.8 \\
4-ANAN & 330 & 0.9999 & $0.2 / 0.6$ & 1.1 \\
\hline
\end{tabular}

\section{Results and Discussion}

Loamy soil used in the static and soil column experiments was selected as it is similar to a specific military training range in the UK. Sandy soil was chosen as it is commonly used as an adsorbent for a variety of military activities. Both soil types were fully characterised to enable understanding of the relationship between soil properties and the fate and transport of the selected explosives. Particularly organic content, as this is known to affect the adsorption and degradation of DNAN and NTO (Arthur et al., 2017; Mark et al., 2017b). Soil PH was also monitored throughout the experiment and remained consistent with the soil $\mathrm{pH}$ prior to addition of the explosive contaminants.

The mass of DNAN, NQ and NTO added to static experiments, and the soil columns was chosen to represent a specific IHE formulation. In order to accurately account for the fate of all constituents, they were added to the soil in solution so that the dissolution rate of the solid did not affect the rate of transport or degradation in the soil. 


\subsection{Static Experiments}

Static experiments were designed to mimic the conditions found in a soil column to investigate the fate of the three IHE constituents, specifically to identify major degradation products in the two soil types. Both the liquid and solid phase were analysed for parent explosive and major degradation products at the specified time points. The liquid phase was isolated by decanting the solution, and taking a $1 \mathrm{ml}$ aliquot which was then diluting in $\mathrm{ACN} /$ water $(1: 1)$. The remaining soil was then treated with ACN/water (1:1), and shaken for 18 hours to extract any remaining explosive to account for explosive adsorbed to the soil. Major degradation products were identified from the literature prior to the experiments, and selected for commercial availability as 2-ANAN, 4-ANAN, DAAN, DNP and 4-HONAN for DNAN. ATO and triazolone (TO) were selected as major NTO degradation products. As NQ is not readily degraded in soil it was not possible to identify NQ degradation products by HPLC.

During the 62-day experiment, the concentrations of DNAN, NQ and NTO recovered from sandy soil remained high, with almost complete recovery of all explosives from the combined liquid and solid phases 93\%, 99\% and 99\% respectively. DNAN and NTO concentration in loamy soil rapidly decreased, suggesting a relationship between DNAN and NTO loss and high concentrations of organic content in the soil, which supports previous literature (Figure 2) (Arthur et al., 2017; Mark, 2014; Olivares et al., 2016). 


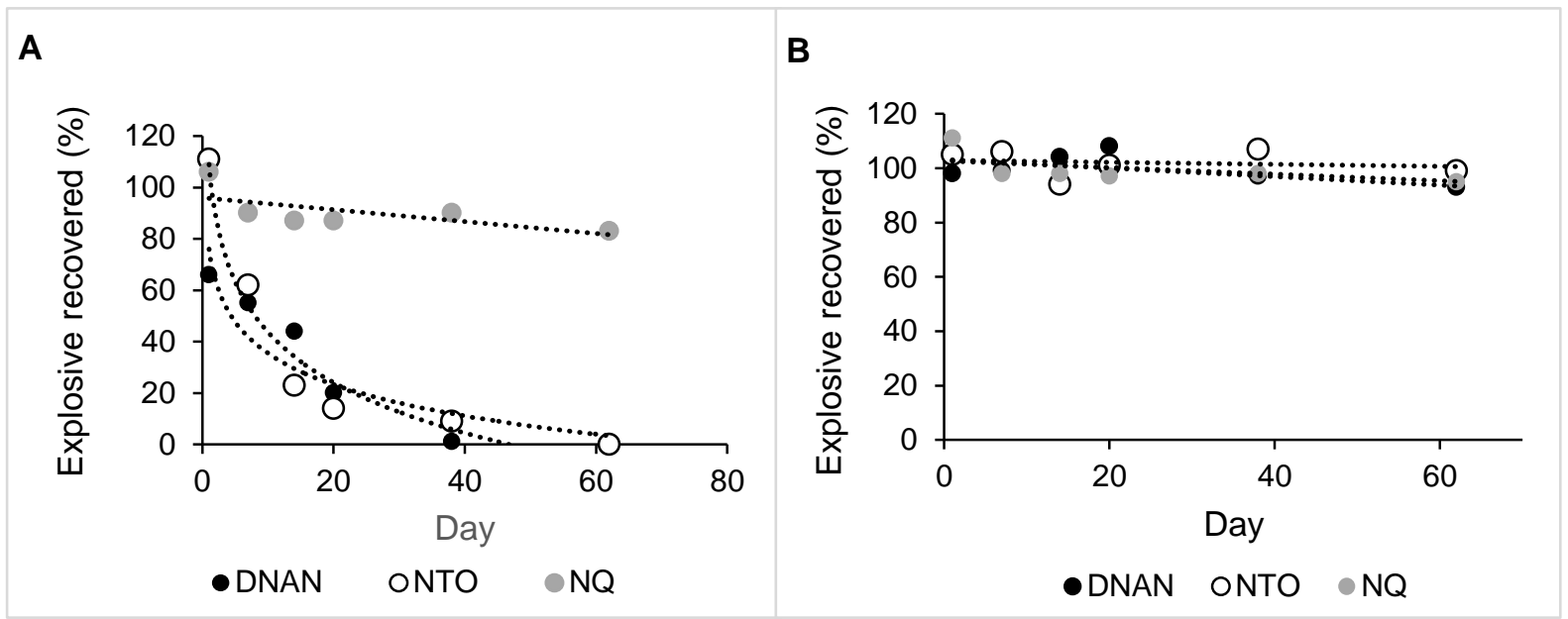

Figure 2 (A): Observed mass loss of DNAN, NQ and NTO in loamy soil static experiments over 62 days with linear or logarithmic trend lines applied; (B): Observed mass loss of DNAN, NQ and NTO in sand soil static experiments over 62 days with linear trend lines applied.

Results were normalised to the percentage of parent compound recovered from the Ottawa sand blank to minimise minor variations in percentage recovery due to changes to room temperature of the calibration standard. DNAN concentration in particular may have been affected by these temperatures changes as the concentration in the stock solution was at saturation. The average percentage recovery of all three explosives from Ottawa sand was $103 \% \pm 3 \%$ compared to Stock Solution 1, confirming that in the absense of soil, DNAN in solution with NTO and NQ, is stable up to nine weeks in the absence of UV. 


\subsubsection{Effect of organic content on fate of DNAN, NQ and NTO}
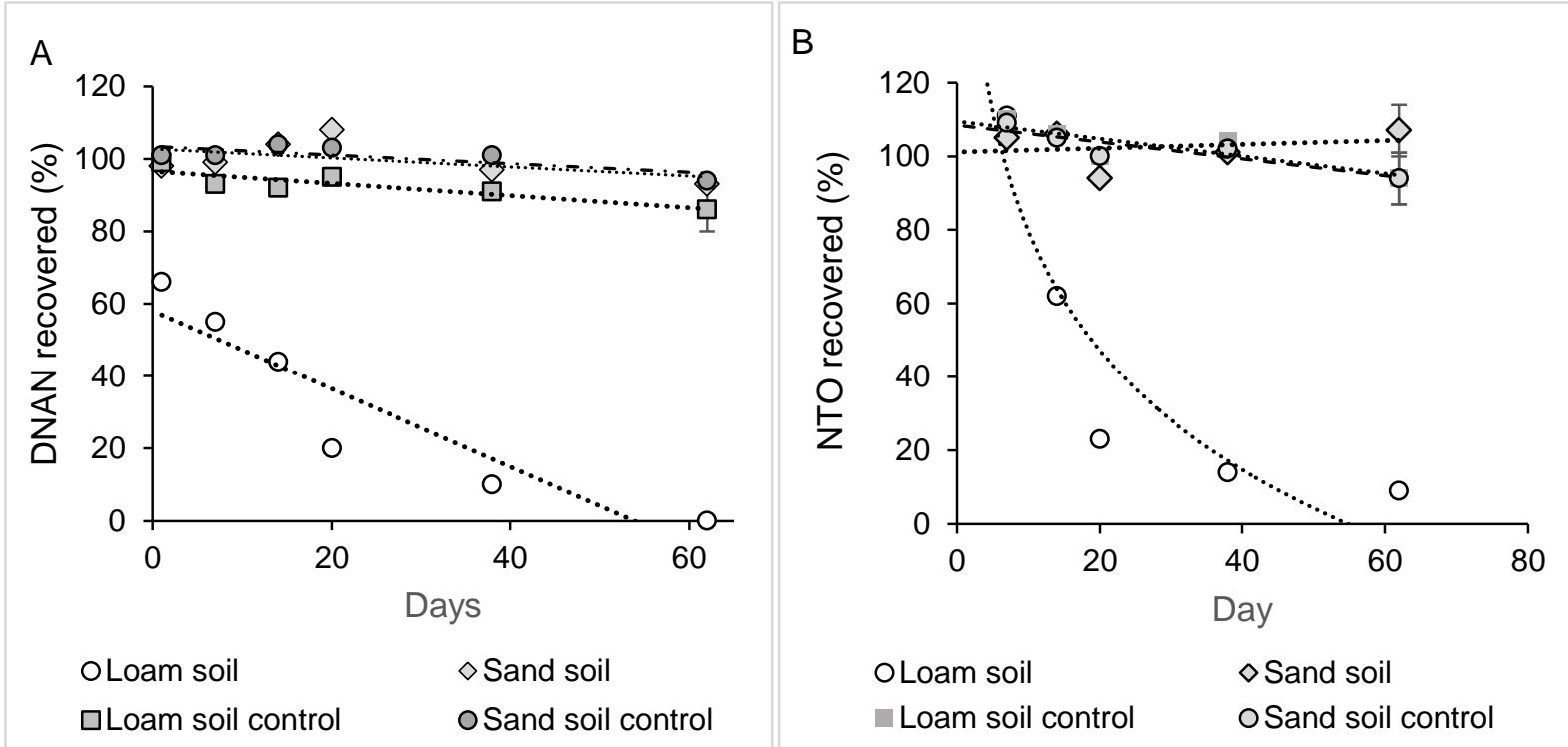

Figure 3: A: Total percentage recovery of DNAN (liquid and solid phase) from loamy soil, sand soil and both control soils with linear trend line applied; B Total percentage recovery of NTO (liquid and solid phase) from loamy soil, sand soil and both control soils with linear or logarithmic trend line applied. All results were normalised to Ottawa sand blank. Day 62 results were averaged from triplicate.

In order to assess the effect of organic content of the degradation of the three explosives, samples of the sandy soil and loamy soil were incinerated to vaporise bio-organisms and organic molecules. A comparison between the total percentage of DNAN and NTO recovered from both the liquid and solid phase of the loamy soil and sandy soil and the two incinerated soil controls is shown in Figure 3. The total percentage of DNAN recovered from loamy soil started to decrease within the first 24 hours, and after 38 days only trace amounts of the initial DNAN were recovered from the solid phase. However, the total percentage recovery of DNAN from incinerated loamy soil was still high after nine weeks, with only $14 \%$ mass loss. This suggests a strong correlation between organic and bio-organic matter and the degradation of DNAN. Due to the high percentage of organic matter in the loamy soil, the incinerated samples still contained some organic matter which contributed to the $14 \%$ observed mass loss. A slight decrease in the total percentage recovery of DNAN from sandy soil was obsereved over the course of experiment, which may be within experimental error. NTO was stable in sandy soil and the sandy control, with $100 \%$ total recovery after 62 days. In loamy soil, the concentration of NTO rapidly decreased in the liquid phase, and was not recoverable from the solid phase, suggesting that 
degradation had occurred. Although rapid mass loss was observed in loamy soil, no NTO loss was observed in the incinerated loamy soil, suggesting a strong correlation between organic content and NTO mass loss.

A slight decrease in the concentration of NQ recovered from the combined liquid and solid phase in loamy soil, sandy soil and the incinerated sandy soil control was observed. It is likely that over prolonged periods of contact with soil, NQ slowly degrades. Mass loss observed in the incinerated sandy control samples was unexpected as NQ recovered from the sandy soil was consistent throughout the experiment averaging $99 \% \pm 6 \%$. Incineration of the sandy soil may change the composition of the soil allowing for an alternative mechanism of mass loss.

\subsubsection{Adsorption of DNAN, NQ and NTOto soil}

The two-stage recovery of explosives from the liquid followed by the solid phase highlighted the strong attenuation of DNAN to soil. In addition, DNAN attenuation to the loamy soil was more pronounced than attenuation to the sandy soil or incinerated sandy control suggesting that DNAN is more likely to adsorb to soils with high organic content, which supports the results of previous studies (Arthur et al., 2017). NTO and NQ did not adsorb significantly to any of the tested soils, and did not display any correlation between organic content of the soil and adsorption in line with current literature (Mark et al., 2016). The adsorption of DNAN to loamy soil was rapid. A liquid extraction after 10 minutes recovered only $53 \%$ of the DNAN. After 24 hours, only $30 \%$ of the DNAN was extractable from the liquid phase, with an additional 53\% extracted from the solid phase (Figure 4). Interestingly, absorption to incinerated loamy soil was equally as rapid as absorption onto the loamy soil, however after 24 hours a higher percentage of DNAN was recovered from the incinerated loamy soil solid phase (94\% compared to $83 \%$ from loamy soil) suggesting faster degradation of DNAN in loamy soil. The DNAN adsorption to the four soils is in line with increasing organic content. 


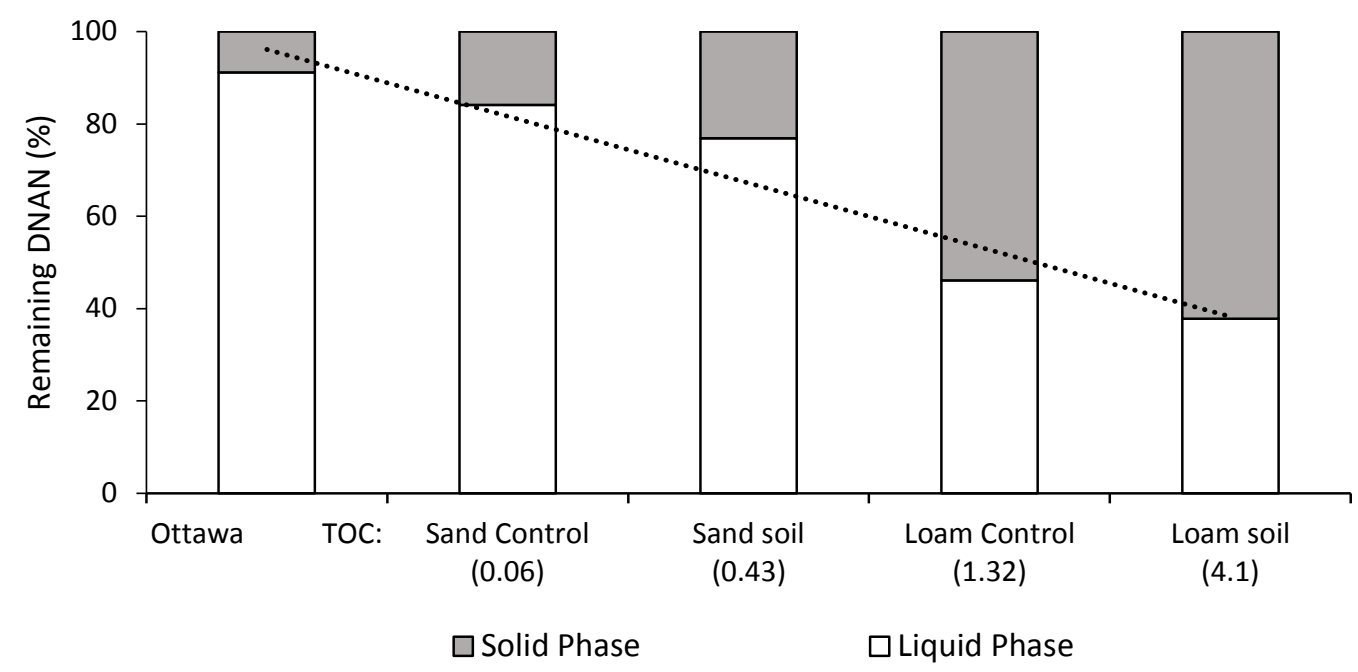

Figure 4: Percentage DNAN recovered from the liquid phase and solid phase at 24 hours normalised to the total percentage DNAN recovered. A linear trend line has been applied.

\subsubsection{Identification of degradation products of DNAN, NQand NTO in soil}

Significant mass loss of DNAN and NTO was observed in loamy soil, as expected due to the high organic content which is thought to contribute to degradation of or sorption of these explosives. In static experiments, as the percentage recovery of DNAN reduced, the degradation products 2 and 4ANAN were generated. As seen in previous literature, we observed that 2-ANAN was the dominant degradation product, with only trace amounts of 4-ANAN recovered (Figure 5) (Arthur et al., 2017; Hawari et al., 2015; Olivares et al., 2016). Although mass loss was far less pronounced in the loamy soil control, trace amounts of 2-ANAN were detected suggesting some degradation which may be attributable to the small amount of organic content remaining in the soil. 


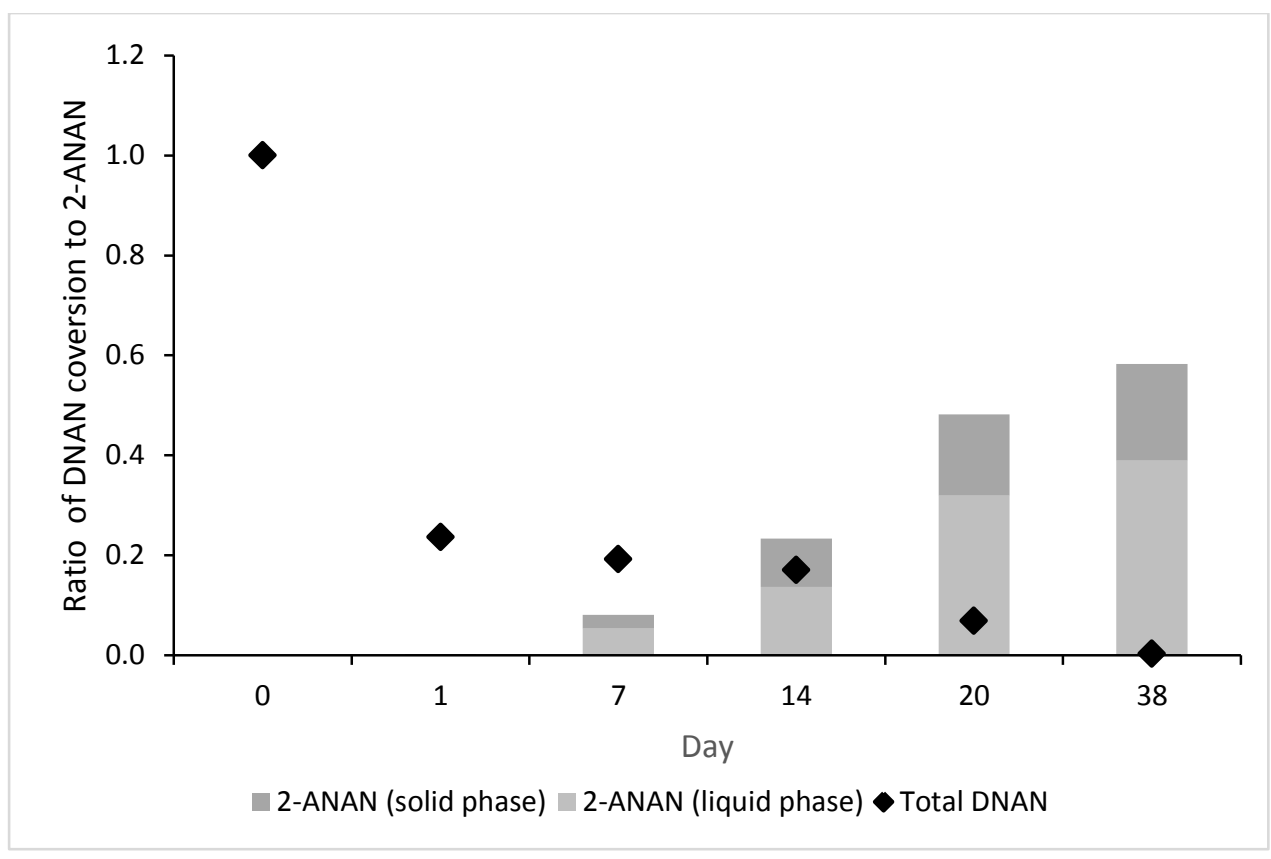

Figure 5: Molar ratio of DNAN converted to 2-ANAN recovered from the solid and liquid phase. The ratio was calculated from the concentration in moles, and assuming stoichiometric transformation.

Although DNAN mass loss was observed within the first 24 hours, significant concentrations of 2ANAN were not recovered from the loamy soil liquid or solid phase until Day 7 . This may be due to the extraction method, which is known to extract DNAN from soil with 100\% efficiency, but has not been proven for 2-ANAN. In addition, 2-ANAN is more likely than DNAN to adsorb to soil both reversibly and irreversibly and so may be more difficult to recover (Hawari et al., 2015). Figure 5 shows that 2-ANAN generation increased for five weeks, however an inconsistently low concentration of 2-ANAN was recovered from day 62 samples even though only trace amounts of DNAN were recovered. Samples on day 62 were taken in triplicate, and results from all three sacrificed samples were consistent. This may be explained by bio-transformation of 2-ANAN to DAAN under both aerobic and anaerobic conditions which has been reported in the literature, (Hawari et al., 2015) however DAAN was not detected in either the solid or the liquid phase at any time point. DAAN is known to be unstable in air, and can form di-azo compounds (Hawari et al., 2015). All experiments were conducted in enclosed vials with a natural atmosphere and exposed to air during analysis therefore dimerization of DAAN may have occurred, possibly explaining the gradual loss of 2-ANAN. 
ATO, the expected degradation product of NTO, was not detected in any of the samples despite almost complete loss of NTO. New peaks were observed in the HPLC trace, but could not be resolved due to the close proximity between the NTO, and NQ peaks. Degradation of NTO was not observed in the loamy control sample, nor the sandy soil suggesting that high organic content is necessary for NTO degradation.

Exposure of the explosive constituents of a new IHE (DNAN, NQ and NTO) to soil under atmospheric conditions showed that in combination DNAN, NQ and NTO are unlikely to interact with one another. The results supported findings in the literature that DNAN and NTO are readily transformed in soils with high organic content most likely by bio-degradation, while NQ is much more stable (Arthur et al., 2017; Hawari et al., 2015; Olivares et al., 2016). In addition, DNAN and its major degradation product 2-ANAN, were more likely to be adsorbed to soil with high organic content.

\subsection{Transport of DNAN, NQand NTO in vertical saturated soil columns}

Soil columns are a well-established method for determining the fate and mobility of contaminants through soil, (Lewis and Sjöstrom, 2010) and have been used to determine transport of explosives (Mark, 2014; Pennington and Brannon, 2002). Soil columns were designed to simulate the mobility of explosive contaminated water through soil matrices, whilst avoiding preferential pathways and sidewall flow. Therefore, we used closely packed saturated vertical columns with a $10 \mathrm{~cm}$ diameter as this has been proven to reduce sidewall effects, and ensure reproducibility between replicates (Lewis and Sjöstrom, 2010). The explosives were introduced to the soil columns in solution, the mass of NTO and NQ was well below the mass required for saturation, however the DNAN did not completely solubilise and was therefore added in suspension. The explosives were added in $150 \mathrm{~mL}$ water, which was then subtracted from the initial dose of water to ensure water delivery was consistent with average annual rainfall in the UK.

The soil columns were treated with water every day totalling the average yearly rainfall for the South West of England, so that the experiment was set in the context of UK rainfall patterns. The columns 
were dosed evenly throughout the five weeks in increments to avoid pooling of water on the column surface. The water leachate was collected and analysed every seven days, starting one week after the first dosing.

\subsubsection{Transport of DNAN, NQ and NTO in sandy soil columns}

Results from static experiments indicated that DNAN, NQ and NTO were not adsorbed nor degraded by sandy soil, therefore recovery of explosive constituents was expected from both liquid and solid phase. While this was true for NTO and NQ, which were fully eluted within the first seven days, complete recovery of DNAN was not achieved from the sandy soil column leachate (Figure 6A). The concentration of DNAN in the eluent gradually decreased, with a cumulative total of $38 \%$. No expected degradation products were identified in the leachate.

After five weeks of water addition- equivalent to one year of rainfall- the columns were disassembled and the soil was extracted by accelerated solvent extraction (ACN/water, 3:2). An additional 18\% of the DNAN was recovered from the top $5 \mathrm{~cm}$ of the sandy soil column, leaving $44 \%$ of DNAN unaccounted for. An equivalent of 5.5\% of the unaccounted DNAN was detected as 2-ANAN in the top $5 \mathrm{~cm}$ of soil, confirming that 2-ANAN is much less mobile in soil than DNAN, even in soils with low organic content. Almost 50\% of the DNAN remained unaccounted for, but the presence of 2ANAN suggests that it most likely degraded first into 2-ANAN, then further degraded possibly to DAAN so that quantitative recovery was not possible.

\subsubsection{Transport of DNAN, NQ and NTO in loamy soil columns}

Of the three explosives, only NQ was observed in the loamy soil columns during the five week experiment, with $81 \%$ of the initial material recovered. NTO and DNAN were not detected in the soil column leachate, which is consistent with their rapid degradation (Figure 6B). However, given NTO's high solubility, and low attenuation to soil, we expected to see some NTO in the leachate during the first few weeks before much of the NTO had time to degrade, as in static experiments NTO took five weeks to fully degrade. The lack of NTO in the leachate suggests that the degradation mechanisms 
can be much quicker in dynamic environments than were seen in the static experiments, which may be due to the much larger mass of soil compared to explosive in the soil columns leading to greater chance of exposure to bio-organisms.

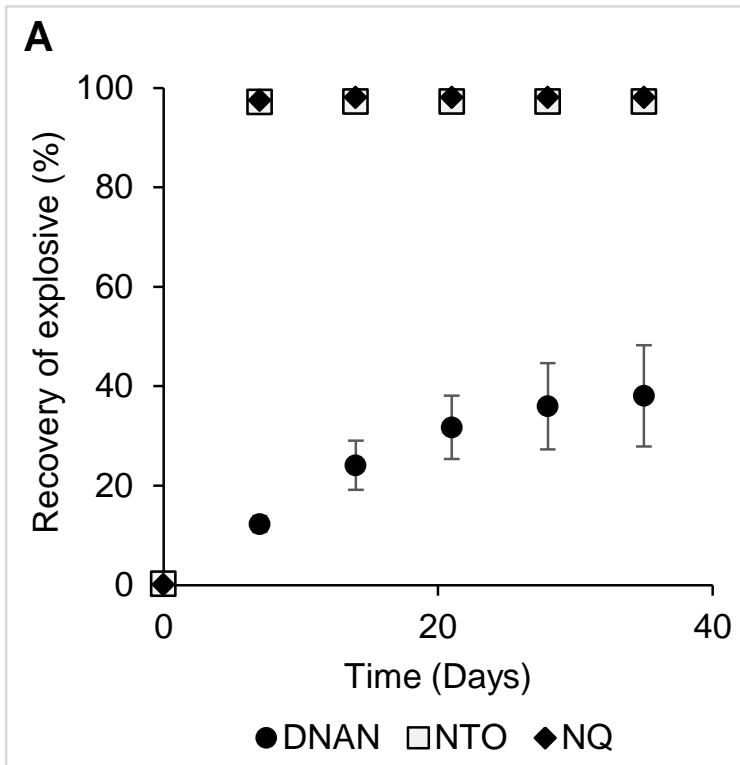

B

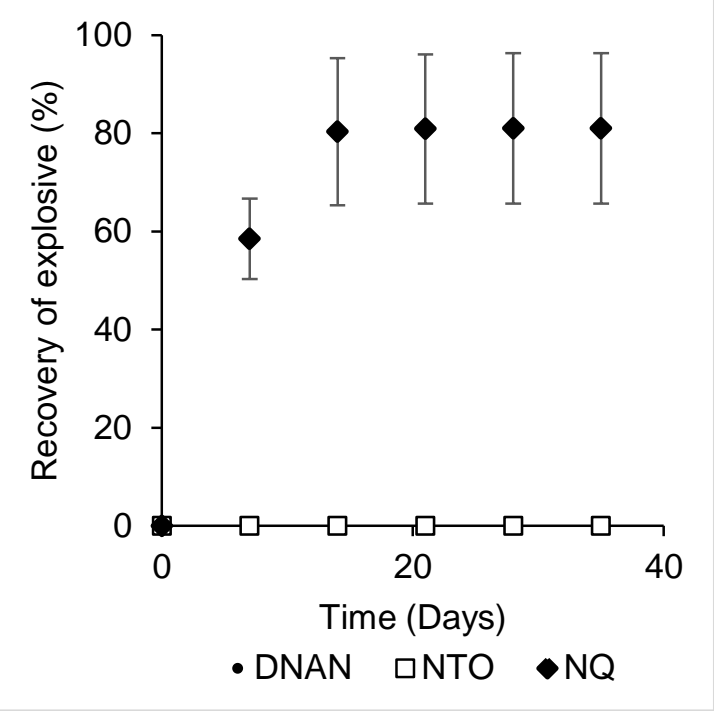

Figure 6: A: Recovery of explosive from sandy soil column leachate averaged over triplicates; B: recovery of explosive from loamy soil column leachate against time averaged over triplicates.

The absence of DNAN in the loamy leachate was expected, as DNAN has a high affinity for the loamy soil, and in static experiments had started to degrade to 2-ANAN within the first seven days. Similarly to the sandy columns, no DNAN degradation products were observed in the leachate, most likely due to their greater attenuation to soil, or rapid degradation into other compounds that were not in the analyte screen. Additionally, DNAN is the least soluble of the three constituents and was added to the columns in suspension. Time taken for DNAN to dissolve would also have slowed down the rate of DNAN transport.

Interestingly, ASE extraction of the loamy soil columns led to the recovery of $19 \%$ DNAN, which is similar to the percentage recovered from sandy soil. This was unexpected, as in loamy soil static experiments all DNAN was degraded within five weeks. However, considering that identical solutions of explosives were added to each column, and a similar percentage of DNAN was recovered from 
both sandy and loamy soil columns, it is likely that the DNAN recovered from the top $5 \mathrm{~cm}$ of soil was undissolved particles from the initial addition.

An equivalent of $8 \%$ 2-ANAN was recovered from the top layer $(5 \mathrm{~cm})$ of the loamy soil columns, leaving $74 \%$ of the original DNAN unaccounted for by primary degradation products. In static experiments the recovery of 2-ANAN was high at five weeks, suggesting there was an increase in the rate of degradation in the soil columns.

Only trace amounts of NTO and NQ were recovered from the loamy soil solid phase, suggesting that all of the initial NTO and $20 \%$ of the NQ was degraded which is consistent with static experiments. Overall, there was good consistency between static experiments and soil column experiments confirming that the fate of DNAN, NQ and NTO observed in static experiments can be used to explain soil column results (Figure 7).

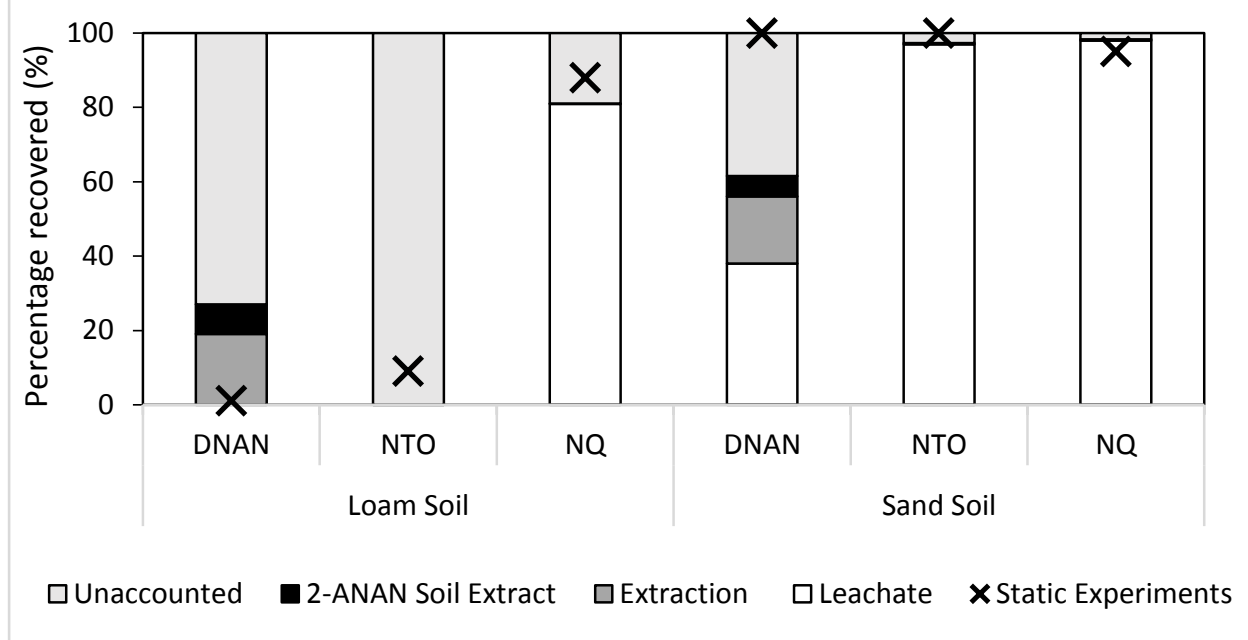

Figure 7: Summary of fate of DNAN, NQ and NTO in soil from static and batch experiments

Less time was required for complete degradation of DNAN, and NTO in soil columns compared to static experiments. The degradation of DNAN in sandy soil columns was particularly interesting due to the low organic content of the soil, and the stability of DNAN in static experiments. In future, it 
would be useful to ensure the ratio of explosive to soil is the same in both static and soil column experiments.

Despite slight differences in results between static and soil column experiments, DNAN, NQ and NTO behaviour supports current literature, and does not seem to be significantly altered by interactions between the three constituents under the evaluated conditions. Future work would benefit from focussing on the secondary degradation products of DNAN e.g. DAAN and its diazo compounds, and to establish NTO degradation products in real soil environments.

\section{Conclusion}

Military training with live fire munitions is essential for troops to maintain combat readiness, and it is inevitable that contamination of soil and groundwater will occur on and around these areas. As training ranges are located on wide variety of soil types it is difficult to predict how explosive contaminants will interact and how specific receptors will be affected. Traditional explosives such as TNT and RDX are well understood in terms of their fate and transport mechanisms although contamination still occurs. It is therefore essential that new IHE, that are being brought into military service, are understood and managed so that contamination can be avoided. This research investigated fate and transport of the combined constituents of an IHE consisting of DNAN, NQ and NTO in static soil experiments and vertical soil columns under controlled laboratory conditions. The static experiments were conducted so that full degradation profiles of the three explosives in varying soil types could be observed prior to conducting soil column experiments. The novelty of this work was the investigation of the three explosives combined rather than individual testing. Results supported work from literature on the individual constituents DNAN, NQ and NTO suggesting that the three explosives in combination did not interact with each other when in soil. This is significant when considering this type of IHE and its environmental impact e.g. adverse interactions due to soil conditions could generate more toxic and persistent contaminants. Both static and soil column experiments confirm that soils with high organic content are more likely to degrade DNAN and NTO. Our results show that when this type of IHE is used on training ranges, the most significant environmental impacts may be from NTO. Even though NTO itself is not significantly toxic, it 
rapidly degrades in the environment into potentially toxic degradation products. DNAN is most likely to degrade in soils with high organic content, although into less toxic products.

\section{Acknowledgements}

The authors would like to acknowledge Rebecca Green for her contribution to the practical work and Cranfield University for the graphics. This work was funded by Cranfield University. This research did not receive any specific grant from funding agencies in the public commercial or not for profit sectors.

\section{References}

Arthur, J.D., Mark, N.W., Taylor, S., Šimunek, J., Brusseau, M.L., Dontsova, K.M., 2017. Batch soil adsorption and column transport studies of 2,4-dinitroanisole (DNAN) in soils. Journal of Contaminant Hydrology 199, 14-23. doi:10.1016/j.jconhyd.2017.02.004

Bordeleau, G., Martel, R., Ampleman, G., Thiboutot, S., 2008. Environmental Impacts of Training Activities at an Air Weapons Range. Journal of Environment Quality 37, 308. doi:10.2134/jeq2007.0197

Braida, W.J., Wazne, M., Ogundipe, A., Tuna, G. Sen, Pavlov, J., Koutsospyros, A., 2012. Transport of Nitrotriazolone (NTO) in Soil Lysimeters, in: Protection and Restoration of the Environment Conference XI. Thessaloniki, Greece.

Crouse, L.C.B., Lent, E.M., Leach, G.J., 2015. Oral Toxicity of 3-Nitro-1,2,4-triazol-5-one in Rats. International journal of toxicology 34, 55-66. doi:10.1177/1091581814567177

Dionex, 2011. Extraction of Explosives from soils by Accelerated Solvent Extraction ( ASE ). Sunnyvale, CA.

Dodd, D.E., McDougal, J.N., 2001. Recommendation of an occupational expsure level for PAX-21; AFRL-HE-WP-TR-2001-0103, Technical Report. U.S. Air Force Armstrong Laboratory, Ohio.

Hawari, J., Monteil-Rivera, F., Perreault, N.N.N., Halasz, A., Paquet, L., Radovic-Hrapovic, Z., Deschamps, S., Thiboutot, S., Ampleman, G., 2015. Environmental fate of 2,4-dinitroanisole (DNAN) and its reduced products. Chemosphere 119, 16-23. doi:10.1016/j.chemosphere.2014.05.047

Jenkins, T.F., Hewitt, A.D., Grant, C.L., Thiboutot, S., Ampleman, G., Walsh, M.E., Ranney, T.A., Ramsey, C.A., Palazzo, A.J., Pennington, J.C., 2006. Identity and distribution of residues of energetic compounds at army live-fire training ranges. Chemosphere 63, 1280-1290. doi:10.1016/j.chemosphere.2005.09.066

Kalderis, D., Juhasz, A.L., Boopathy, R., Comfort, S., 2011. Soils contaminated with explosives: Environmental fate and evaluation of state-of-the-art remediation processes (IUPAC Technical Report). Pure and Applied Chemistry 83, 1407-1484. doi:10.1351/PAC-REP-10-01-05

Kaplan, D.L., Kaplan, A.M., 1985. Degradation of Nitroguanidine in Soils. Natick.

Krzmarzick, M.J., Khatiwada, R., Olivares, C.I., Abrell, L., Sierra-Alvarez, R., Chorover, J., Field, J.A., 2015. Biotransformation and degradation of the insensitive munitions compound, 3-nitro- 
1,2,4-triazol-5-one, by soil bacterial communities. Environmental Science and Technology 49, 5681-5688. doi:10.1021/acs.est.5b00511

Le Campion, L., Giannotti, C., Ouazzani, J., 1999. Photocatalytic degradation of 5-Nitro-1,2,4Triazol-3-one NTO in aqueous suspention of $\mathrm{TiO} 2$. Comparison with fenton oxidation. Chemosphere 38, 1561-1570. doi:10.1016/S0045-6535(98)00376-2

Lee, K.-Y., Coburn, M.D., 1988. 3-nitro-1,2,4,-triazol-5-one, a less sensitive explosive. 4,733,610.

Lee, K.E., Balas-Hummers, W.A., Di Stasio, A.R., Patel, C.H., Samuels, P.J., Roos, B.D., Fung, V., 2010. Qualification testing of the insensitive TNT replacement explosive IMX-101, in: Insensitive Munitions and Energetic Materials Technology Symposium. pp. 1-13.

Lewis, J., Sjöstrom, J., 2010. Optimizing the experimental design of soil columns in saturated and unsaturated transport experiments. Journal of contaminant hydrology 115, 1-13. doi:10.1016/j.jconhyd.2010.04.001

Mark, N., Arthur, J., Dontsova, K., Brusseau, M., Taylor, S., 2016. Adsorption and attenuation behavior of 3-nitro-1,2,4-triazol-5-one (NTO) in eleven soils. Chemosphere 144, 1249-1255. doi:10.1016/j.chemosphere.2015.09.101

Mark, N., Arthur, J., Dontsova, K., Brusseau, M., Taylor, S., Šimůnek, J., 2017a. Column transport studies of 3-nitro-1,2,4-triazol-5-one (NTO) in soils. Chemosphere 171, 427-434. doi:10.1016/j.chemosphere.2016.12.067

Mark, N., Arthur, J., Dontsova, K., Brusseau, M., Taylor, S., Šimůnek, J., 2017b. Column transport studies of 3-nitro-1,2,4-triazol-5-one (NTO) in soils. Chemosphere 171, 427-434. doi:10.1016/j.chemosphere.2016.12.067

Mark, N.W., 2014. Batch and Column Transport Studies of Environmental Fate of 3-nitro-1,2,4triazol-5-one (NTO) in Soils. The University of Arizona.

McCain, W., Williams, L., Grunda, R., 2013. Toxicology Portfolio In Vitro Dermal Absorption of Insensitive Munitions Explosive 101 ( IMX-101 ) and Components, December 2011 - July 2012 Prepared by Dr. Wilfred McC. US Army Public Health Command 1, 1-9.

Met Office, n.d. Met Office Hadley Centre Observation Data. http://www.metoffice.gov.uk/hadobs/hadukp/data/download.html. doi:10.1006/asle.2001.0025

Mirecki, J.E., Porter, B., Weiss, C.A., 2006. Environmental Transport and Fate Process Descriptors for Propellent Compounds ERDC/EL TR-06-7.

Morley, M.C., Yamamoto, H., Speitel, G.E., Clausen, J., 2006. Dissolution kinetics of high explosives particles in a saturated sandy soil. Journal of Contaminant Hydrology 85, 141-158. doi:10.1016/j.jconhyd.2006.01.003

Olivares, C.I., Abrell, L., Khatiwada, R., Chorover, J., Sierra-alvarez, R., Field, J.A., 2016. (Bio) transformation of 2, 4-dinitroanisole ( DNAN ) in soils. Journal of Hazardous Materials 304, $214-221$.

Oliviera, I.B., Demond, A.H., Salehzadeh, A., 1996. Packing of Sands for the Production of Homogeneous Porous Media. Soil Science Society of America Journal 60, 49. doi:10.2136/sssaj1996.03615995006000010010x

Pennington, J.C., Brannon, J.M., 2002. Environmental fate of explosives. Thermochimica Acta 384, 163-172. doi:10.1016/S0040-6031(01)00801-2

Pichtel, J., Pichtel, J., 2012. Distribution and fate of military explosives and propellants in soil: A review. Applied and Environmental Soil Science 2012, 1-33. doi:10.1155/2012/617236

Rao, B., Wang, W., Cai, Q., Anderson, T., Gu, B., 2013. Photochemical transformation of the 
insensitive munitions compound 2,4-dinitroanisole. Science of The Total Environment 443, 692-699. doi:10.1016/j.scitotenv.2012.11.033

Richard, T., Weidhaas, J., 2014a. Biodegradation of IMX-101 explosive formulation constituents: 2,4dinitroanisole (DNAN), 3-nitro-1,2,4-triazol-5-one (NTO), and nitroguanidine. Journal of Hazardous Materials 280, 561-569. doi:10.1016/j.jhazmat.2014.08.042

Richard, T., Weidhaas, J., 2014b. Biodegradation of IMX-101 explosive formulation constituents: 2,4-Dinitroanisole (DNAN), 3-nitro-1,2,4-triazol-5-one (NTO), and nitroguanidine. Journal of Hazardous Materials 280, 372-379. doi:10.1016/j.jhazmat.2014.08.019

Singh, S., Jelinek, L., Samuels, P., Stasio, A. Di, Zunino, L., 2010. IMX-104 Characterization for DoD Qualification, in: 2010 Insensitive Munitions and Energetic Materials Technology Symposium. Munich, Germany, October.

Smith, M.W., Cliff, M.D., 1999. NTO-Based Explosive Formulations: A Technology Review. Report: DSTO-TR-0796. Weapons Systems Division, Aeronautical and Maritime Research Laboratory.

Taylor, S., Dontsova, K., Walsh, M.E.M.R., Walsh, M.E.M.R., 2015. Outdoor dissolution of detonation residues of three insensitive munitions (IM) formulations. Chemosphere 134, 250256. doi:10.1016/j.chemosphere.2015.04.041

Taylor, S., Walsh, M.E., Becher, J.B., Ringelberg, D.B., Mannes, P.Z., Gribble, G.W., 2017. Photodegradation of 2,4-dinitroanisole (DNAN): An emerging munitions compound. Chemosphere 167, 193-203. doi:10.1016/j.chemosphere.2016.09.142

The Environmental Permitting (England and Wales) Regulations 2010. SI 675., 2010. . England and Wales.

United States Environmental Protection Agency, 2014a. Technical Fact Sheet - 2,4,6-Trinitrotoluene (TNT)

United States Environmental Protection Agency, 2014b. Technical Fact Sheet - Hexahydro-1,3,5trinitro-1,3,5-triazine (RDX).

Walsh, M.E., 2016. Analytical Methods for Detonation Residues of Insensitive Munitions. Journal of Energetic Materials 34, 76-91. doi:10.1080/07370652.2014.999173

Walsh MR., Walsh ME., Collins CM., Saari S P., Zufelt J E., Gelvin AB., and Hug J W., 2005. Residues from Live-Fire Detonations of 120-mm Mortar Rounds.

Williams, L.R., Eck, W.., Johnson, M.S., 2014. Toxicity of IMX Formulations and Components: What we know and Path Forward, in: JANNAF Workshop Proceedings. pp. 92-104. 